\title{
РОССИЙСКИЕ СПЕКТРОМЕТРЫ ДЛЯ КОНТРОЛЯ СОСТАВА МЕТАЛЛОВ
}

Олег ТОРОНОВ
Научно-производственное предприятие ООО «Спектральная лаборатория» создано в 1992 году в Санкт-Петербурге группой специалистов, имеющих многолетние традиции в разработке оптических, механических, электронных узлов и аппаратуры, опыт работы на производстве спектрометрического оборудования и большой научноисследовательский потенциал. Основное направление деятельности компании - разработка и производство новой техники для спектрального анализа состава металлов и других материалов.

\section{ОПТИЧЕСКИЕ ЭМИССИОННЫЕ СПЕКТРОМЕТРЫ НА ПРОИЗВОДСТВЕ}

Метод эмиссионного спектрального анализа сегодня широко распространен при определении элементного состава вещества и применяется в различных отраслях: в черной и цветной металлургии, при добыче, обогащении и переработке руды, сырья и минералов, получении изделий и материалов высокой чистоты, экологическом контроле пищевой продукции, переработке ядерных отходов и др.

Получить точную информацию об исследуемом веществе помогают недорогие и популярные приборы - эмиссионные спектрометры, которые за несколько десятков секунд могут определить марку и полный химический состав металла. Стационарные спектрометры необходимы там, где важна максимальная точность анализа, например, в экспресс-лабораториях плавильных цехов для оперативного контроля состава металла в печи. Благодаря высокоточному спектрометру можно вести плавку на нижних пределах и экономить дорогостоящие легирующие материалы.

Мобильные оптические эмиссионные спектрометры часто применяются для оперативного контроля закупаемого металла с целью подтверждения сертификата, для разбраковки металлоотходов или сортировки обезличенного металла, а также определения марки металла в деталях или готовых изделиях.

\section{НОВОЕ ПОКОЛЕНИЕ СПЕКТРОМЕТРОВ}

Наиболее востребованы на рынке аналитического оборудования спектрометры с твердотельными приемниками света - приборами с зарядовой связью (ПЗС-линейки). Их появление позволило резко сократить габариты и уменьшить стоимость спектрометров, а также расширить спектр определемых на одном приборе элементов.

Специалисты ООО «Спектральная лаборатория» разработали и наладили серийный выпуск современного стационарного оптического эмиссионного спектрометра «MCA II» V5, который пользуется большой популярностью у потребителей.

Спектрометр «MCA II» V5 - небольшой настольный, экономичный в эксплуатации, но наиболее точный оптический эмиссионный спектрометр на ПЗС-линейках. Благодаря увеличенному радиусу круга Роуланда ( $\mathrm{R}=500$ мм) и дифракционной решетке (2400 штр/мм) прибор имеет наилучшее спектральное разрешение среди аналогов. Разработчикам удалось снизить пределы обнаружения, получить максимально чистый спектр без наложения линий, компенсировать астигматизм путем оптимизации оптических схем для использования линейных приемников излучения. Прибор предназначен для точного экспресс-анализа химического состава любых металлов, сплавов как при технологическом процессе выплавки металла, так и анализе готовой продукции на металлургических производствах, а также входном контроле марочного состава деталей, изделий в машиностроении и других отраслях. Количество одновременно определяемых элементов не ограничено. Диапазоны концентраций - от десятитысячных долей процента до 40-50\%. Успешно работает около 200 спектрометров этой серии.

Спектрометр может комплектоваться пистолетом на длинном кабеле и столиком на колесах для анализа крупных деталей, отливок, изделий без отрезания образца.

Главные преимущества прибора - термостабилизация оптики и коррекция мощности для работы 


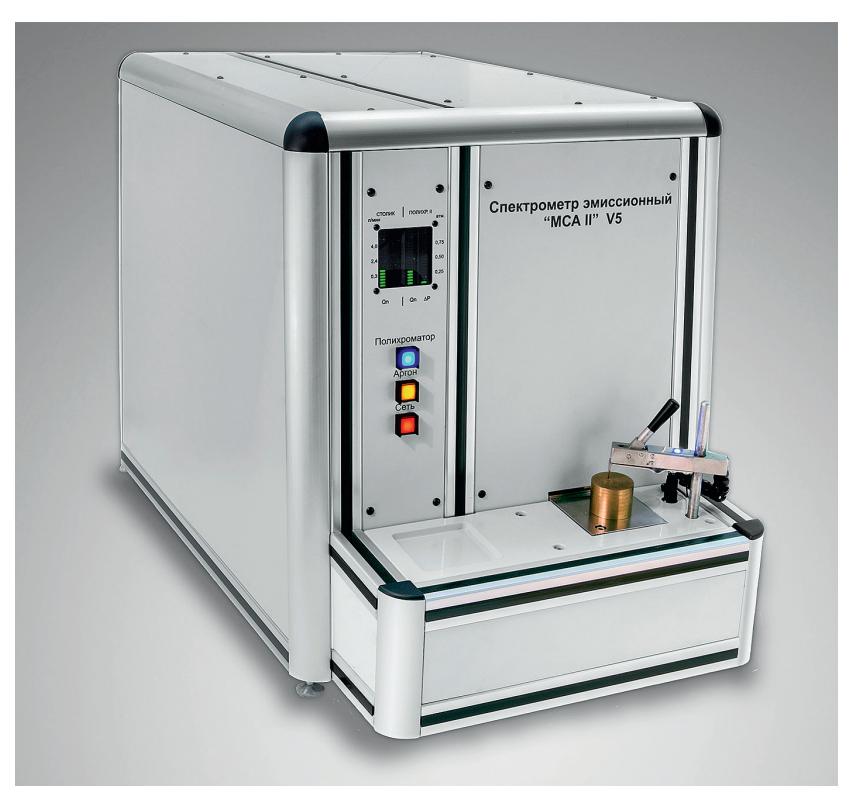

Эмиссионный спектрометр «MCA II» V5

в реальных заводских условиях с «плавающим» электропитанием и изменениями температуры воздуха. Прибор оснащен ПО для количественного анализа химического состава, качественного анализа материалов по их спектру и автоматического определения марки.

На ПЗС-линейках сконструирован и первый российский мобильный эмиссионный спектрометр «Минилаб СЛ», который определяет марку и состав металла прямо на месте его расположения, без отрезания образца. Он выгодно отличается от рентгеновских инструментов уникальной способностью идентифицировать легкие элементы, такие как углерод, магний, алюминий, без определения которых правильная сортировка сталей и других сплавов невозможна. Регистрируемая область спектра от 185 до 406 нм, производительность до 800 анализов в смену, минимальное время накопления спектра 0,015 с. Марку металла можно определить автоматически, благодаря современному программному обеспечению. Прибор легко передвигается по цеху или складу, имеет пистолет на гибком трехметровом кабеле, снабжен системой автономного электропитания, функционирует с продувкой камеры воздухом либо аргоном, оснащен встроенным коррек- тором мощности для работы при напряжении 180-240 B.

Все спектрометры внесены в Государственный реестр средств измерений.

\section{ДОПОЛНИТЕЛЬНОЕ ОБОРУДОВАНИЕ ДЛЯ ЛАБОРАТОРИИ}

ООО «Спектральная лаборатория» выпускает специализированный фрезерный станок-автомат СПП-30 для прецизионной подготовки к спектральному анализу поверхности проб черных и цветных металлов. СПП-30 разработан специально для лабораторий спектрального и рентгеноспектрального анализов и предназначен для лаборантов, не имеющих высокой квалификации или специальных допусков на работу со станками.

Разрядные камеры спектрометров продуваются аргоном, качество которого должно быть гарантировано. ООО «Спектральная лаборатория» выпускает уникальные 4-ступенчатые стенды очистки и осушки аргона «Эпишур-А СЛ», которые можно использовать для любых спектрометров, а также в других технологических процессах. Устройство «Эпишур-А СЛ» является эффективным средством получения действительно чистых газов и может быть использован для решения широкого спектра исследовательских и производственных задач, требующих чистой инертной среды или заданного газового состава в герметичных камерах (боксах), технологических установках и помещениях.

\section{ПРОГРАММА ПОДДЕРЖКИ ПОЛЬЗОВАТЕЛЕЙ}

Компания-производитель спектрометров разработала специальную программу поддержки пользователей, которая гарантирует оперативную помощь, поддержку в течение не менее 12 лет, систему «трейд-ин» по замене устаревших спектрометров, льготы по приобретению станков для пробоподготовки, установок очистки аргона, повторному обучению.

тоРонов Олег Григорьевич -

генеральный директор 000 «Спектральная лаборатория»

000 «Спектральная лаборатория»

СПЕКТРАЛЬНАЯ

ЛАБОРАТОРИЯ
195009, Санкт-Петербург, а / я 115

+7 812 385-14-53, 331-76-57, +7 921 960-76-64

Эл. почта: in@spectr-lab.ru

Сайт: www.spectr-lab.ru 